\title{
The GNAS 393 T>C Polymorphism and the Blood Pressure Response Immediately Following Aerobic Exercise Among Men with Elevated Blood Pressure
}

\author{
Linda S. Pescatello ${ }^{\mathrm{a},{ }^{*}}$, Bruce E. Blanchard ${ }^{\mathrm{a}, \mathrm{b}}$, Gregory J. Tsongalis ${ }^{\mathrm{d}}$, Carl M. Maresh ${ }^{\mathrm{a}}$, \\ Brian Griffiths ${ }^{\mathrm{a}}$ and Paul D. Thompson ${ }^{\mathrm{c}}$
}

${ }^{a}$ Department of Kinesiology, University of Connecticut, Storrs, CT, USA; ${ }^{b}$ Department of Pathology, and Division of Cardiology, ${ }^{c}$ Hartford Hospital, Hartford, CT, USA and ${ }^{d}$ Department of Pathology, Dartmouth Medical School and Dartmouth-Hitchcock Medical Center, Lebanon, NH, USA

\begin{abstract}
A common silent single nucleotide polymorphism (393 T $>$ C) in exon 5 of the guanine nucleotide-binding protein system $\alpha$ subunit (GNAS) gene associates with hypertension, and altered autonomic nervous system function and response to $\beta$-blockade. We examined the effects of GNAS $393 \mathrm{~T}>\mathrm{C}$ on the acute post-exercise BP response among 48 Caucasian men (mean \pm SEM, $43.7 \pm 1.4 \mathrm{yr}$ ) with hypertension $(145.1 \pm 1.5 / 85.5 \pm 1.1 \mathrm{mmHg}$ ). Subjects self disclosed a family history of hypertension. Experiments were non-exercise control and 2 exercise bouts at 40\% (LIGHT) and 60\% (MODERATE) of peak oxygen uptake. Subjects left the laboratory with an ambulatory BP monitor. Genotypes were detected using polymerase chain reaction and restriction enzyme digestion. Repeated measure ANCOVA tested if BP differed over time among experiments and GNAS genotypes $(n=37, T T / T C ; n=11, C C)$. Systolic BP increased 8.0 \pm 3.6 $\mathrm{mmHg}$ less $(\mathrm{p}<0.05)$ and diastolic BP tended to decrease $5.1 \pm 2.8 \mathrm{mmHg}$ more $(\mathrm{p}=0.076)$ after LIGHT vs. non-exercise control among men with the GNAS $\mathrm{T}^{393}$ allele than CC homozygotes. There were no genotype differences in BP after MODERATE $v s$. non-exercise control $(\mathrm{p} \geq 0.05)$. Most men with the GNAS $\mathrm{T}^{393}$ allele and a family history of hypertension had lower BP after LIGHT (18/20) vs. non-exercise control; whereas $64 \%$ of men with the GNAS CC genotype did not have lower BP after LIGHT (7/11), independent of family history of hypertension ( $\mathrm{p}<0.01)$. Men with the GNAS $\mathrm{T}^{393}$ allele, a family history of hypertension, and high BP appear to experience the antihypertensive effects of lower intensity, aerobic exercise more so than men with the GNAS CC genotype.
\end{abstract}

Keywords: G protein, genetics, hypertension, physical activity.

\section{INTRODUCTION}

Guanine nucleotide-binding system $\left(\mathrm{G}_{\mathrm{s}}\right)$ proteins are expressed in all cells and involved in nearly all cellular signal transduction processes [1-4]. $\mathrm{G}_{\mathrm{s}}$ proteins are heterotrimers composed of $\alpha-, \beta$-, and $\gamma$-subunits that determine receptor type and effector specificity. The $\alpha$-subunit of $\mathrm{G}_{\mathrm{s}}$ protein couples $\beta$-adrenoceptor activation to the stimulation of cyclic adenosine monophosphate (cAMP). cAMP then stimulates a variety of cAMP dependent protein kinases that modulate short term responses such as changes in potassium and calcium conductance and long term changes such as alterations in gene transcription and cell metabolism [2]. In the cardiovascular system, these actions have important roles in the regulation of cardiac output and peripheral vascular resistance $[5,6]$. Abnormalities in the $\mathrm{G}_{\mathrm{s}}$ protein-linked pathway are associated with hypertension in rat models $[7,8]$. In humans a common silent single nucleotide polymorphism (SNP), $393 \mathrm{~T}>\mathrm{C}(\mathrm{rs} 7121)$, of the $\mathrm{G}_{\mathrm{s}}$ gene in exon 5 of chro-

Address correspondence to this author at the University of Connecticut, Department of Kinesiology, Human Performance Laboratory, Neag School of Education, 2095 Hillside Road, U-1110, Storrs, CT 06269-1110, USA; Tel: (860) 486-0008; Fax: (860) 486-1123;

E-mail: Linda.Pescatello@uconn.edu mosome 20 (20q13.2) that encodes the $\alpha$ subunit (GNAS) is associated with hypertension $[5,7,9]$, and altered autonomic nervous system function [10] and response to $\beta$-blockade [6].

Aerobic exercise training decreases blood pressure (BP) $5-7 \mathrm{mmHg}$ [11], and is recommended as lifestyle therapy to prevent, treat and control hypertension [12]. Some if not all of the BP lowering effects of aerobic exercise training programs result from the acute or immediate BP benefits of a single exercise session, termed post-exercise hypotension (PEH) [13]. However, PEH does not occur in 25\% to 33\% of the people with hypertension [14]. When PEH occurs, the greatest BP reductions occur in those with the highest resting $\mathrm{BP}[11,14,15]$. The heterogeneity of the individual response to the antihypertensive effects of aerobic exercise is attributed to hypertension being a multifactorial, polygenic disorder [16]; and interactions among genetic, neurohormonal and environmental factors that are not well understood [3, 17].

We have recently found that "risk" alleles in genetic variants of the renin angiotensin system $[18,19]$ and the $\alpha$ adducin $\operatorname{Trp}^{460}$ risk allele [20] associate with the immediate BP lowering effects of a session of cycle exercise performed at $40 \%$ of peak oxygen uptake $\left(\mathrm{VO}_{2}\right.$ peak) but not $60 \%$ $\mathrm{VO}_{2}$ peak. GNAS $393 \mathrm{~T}>\mathrm{C}$ has complex hemodynamic ex- 
pression patterns that are dependent upon interactions among the risk status of the population and the level of sympathetic nervous system stimulation induced by the lifestyle behavior examined [5-7, 9]. Nieminen and colleagues [21, 22] investigated the influence of GNAS $393 \mathrm{~T}>\mathrm{C}$ on the acute BP response to maximum exercise among young men with normal $\mathrm{BP}$, and found no clinically significant GNAS genotype associations with the post-exercise BP response.

We now extend our search for candidate SNPs that account for some of the variability in the antihypertensive effects of acute aerobic exercise to GNAS $393 \mathrm{~T}>\mathrm{C}$. The GNAS $\mathrm{T}^{393}$ allele associates with hypertension [5, 7, 9], lower sympathovagal activity in response to postural perturbation [10], and poor response to $\beta$-blockade [6]; actions attributed to reduced cAMP vasodilation of the resistance arteries associated with carrying the GNAS $\mathrm{T}^{393}$ allele. Our work indicates that risk alleles of genetic variants in BP regulatory pathways associate with the immediate antihypertensive effects of lower intensity, aerobic exercise but not with more vigorous levels of physical exertion [18-20]. For these reasons, we hypothesized that men with the GNAS T ${ }^{393}$ allele would lower BP to a greater degree immediately following lower intensity, aerobic exercise compared to men with the GNAS CC genotype; and consistent with our work [18-20] and the findings of Nieminen et al. [6, 21], these GNAS genotype associations would no longer be apparent at more vigorous levels of physical exertion.

\section{METHODS}

\section{Subjects}

Potential subjects were recruited from the surrounding community and places of work via flyer postings and email distribution. As part of the enrollment procedures, volunteers completed a detailed medical health information questionnaire containing questions about caffeine, alcohol, smoking and exercise habits; family history of hypertension; medication use; and presence or absence of various medical diseases and conditions. Volunteers were not enrolled in the study if they had a $\mathrm{SBP} \geq 160 \mathrm{mmHg}$ and/or $\mathrm{DBP} \geq 100 \mathrm{mmHg}$, symptomatic atherosclerotic cardiovascular disease, diabetes mellitus, asthma, thyroid dysfunction, pancreatitis, acute illness, and/or were on medication for depression. Subjects were 48 Caucasian men from 18 to $55 \mathrm{yr}$ with high normal to Stage 1 hypertension [systolic BP (SBP) $\geq 130-159$ and/or diastolic BP $(\mathrm{DBP}) \geq 85-99 \mathrm{mmHg}$. They were sedentary, had no physical limitations that prevented exercise, and did not smoke. Subjects signed an informed consent approved by the Institutional Review Boards of the University of Connecticut and Hartford Hospital.

Any medications potentially influencing the BP response to exercise including antihypertensives, antilipemics, aspirin, non-steroidal anti-inflammatories, nutritional supplements with the exception of a 1-a-day vitamin, cold medications, and herbal supplements were stopped at least $4 \mathrm{wk}$ before testing occurred. When antihypertensives were withdrawn, study investigators regularly monitored participants' BP during the washout period. Men in who the cessation of antihypertensive medication resulted in resting $S B P \geq 160$ and/or $\mathrm{DBP} \geq 100 \mathrm{mmHg}$ were excluded and told to resume their medication.

\section{Procedures}

The methods of this investigation have been published $[15,18-20]$. Briefly, subjects completed an orientation session to acquaint them with the study procedures and determine if their BP met the inclusion criteria. BP was measured in the seating position 3 times, 5 min apart in both arms by auscultation with a mercury sphygmomanometer to the disappearance of the fifth Kortokoff sound and averaged. Waist circumference was measured with a Gulick tape measure (Sammons Preston, Chicago, IL), and height and weight were taken on a standard balance beam scale (Model 339, Detecto, Webb City, MO) and used to calculate body mass index $\left(\mathrm{kg} / \mathrm{m}^{2}\right)$.

During the orientation session, subjects were asked again to self disclose a family history of hypertension among first degree relatives as a yes $(n=23)$ or no $(n=25)$. Participants were instructed not to ingest any caffeinated beverage the morning of the testing sessions and to drink caffeinated $[\leq$ $480 \mathrm{ml}(2$ cups $)]$ and alcoholic $(\leq 2$ drinks/d) beverages in moderation throughout study participation. Otherwise, subjects were asked to maintain their usual diet. Weight maintenance was defined as $\pm 2.25 \mathrm{~kg}(5.0 \mathrm{lb})$ of orientation weight and used as an indication that subjects were adhering to their normal dietary patterns throughout the study. Men were weighed prior to the exercise test and the 3 experiments to ensure weight maintenance.

At the end of the orientation session, an ambulatory BP monitor (Accutracker II automatic noninvasive ambulatory BP monitor, Suntech Medical Instruments Inc., Raleigh, NC) was connected to each subject to acquaint them with the apparatus and ensure their BP met the study inclusion criteria. The same investigator attached the ambulatory BP monitor to all subjects. A calibration check was performed with a mercury manometer and a t-tubule (part \# 98-0030-00). This arrangement enabled the investigator to hear the Korotkoff sounds determined by the mercury manometer and reference them with the ambulatory BP monitor readings. The calibration check consisted of 3 test runs to ensure that 3 successive ambulatory BP measurements were within $5 \mathrm{mmHg}$ of the auscultatory BP determinations made with the mercury manometer. The intra-investigator coefficient of variation between the ambulatory BP monitor and auscultatory mercury manometer BP measurements was $0.7 \%$ for SBP and $1.8 \%$ for DBP. The ambulatory $\mathrm{BP}$ monitor was programmed to record BP about every $20 \mathrm{~min}$. BP was taken 3 times per hour until 2300 hours. All subjects exited the laboratory with instructions to proceed with their usual activities, not to perform formal exercise for the remainder of the day, to let their arm remain still while the monitor was recording, to record any usual emotional or physical events in a diary, and to return the monitor and diary the next day. The computerized ambulatory BP recordings were considered acceptable if at least $80 \%$ of the potential BP readings were obtained. In the rare instance when at least $80 \%$ of the potential BP readings were not obtained, experiments were repeated.

Participants then completed a peak graded cardiopulmonary exercise stress test that was used to determine the workload of the 2 experimental exercise sessions. The graded exercise stress test was performed on a cycle ergometer (Monark Ergomedic 818E, Stockholm, Sweden). The proto- 
col consisted of 2 min incremental stages of continuous cycling at a constant cadence of $60 \mathrm{rev} . \mathrm{min}^{-1}$ with the resistance increased each stage by $0.5 \mathrm{kp}(30 \mathrm{~W})$ until volitional exhaustion. $\mathrm{VO}_{2}$ peak was determined with breath by breath analysis of expired gases (Sensormedics Vmax 29 Metabolic Chart, SensorMedics Corp., Yorba Linda, CA). Heart rate (HR) was recorded continuously with a 12 lead ECG system. The same investigator measured BP by auscultation $30 \mathrm{~s}$ prior to the end of each 2 min stage. At the conclusion of the graded cardiopulmonary exercise stress test, subjects were again instrumented with the same ambulatory monitor to further familiarize them with the apparatus.

Subjects completed 3, 40 min experiments in random order on 3 separate days that were at least $48 \mathrm{~h}$ apart to avoid acute exercise effects on BP $[11,15]$. Each experiment began with a 20 min baseline period of seated rest during which BP and HR were recorded every $2 \mathrm{~min}$. HR was obtained with a HR monitor (Model \# 1902750, Polar Electro Inc, Woodbury, NY), and BP by auscultation in the nondominant arm (i.e. hand with which the subject did not write). The same study investigator made all BP determinations during every experiment for all subjects. All BP measurements taken during the baseline period were averaged and denoted as baseline BP. At the conclusion of the $20 \mathrm{~min}$ baseline period, volunteers performed either a $40 \mathrm{~min}$ non-exercise control session of seated rest; or a 30 min cycle bout on an upright ergometer at light $\left(40 \% \mathrm{VO}_{2}\right.$ peak, LIGHT; equivalent in physical exertion to comfortable walking) or moderate intensity $\left(60 \% \quad \mathrm{VO}_{2}\right.$ peak, MODERATE; equivalent in physical exertion to jogging) with a 5 min warm up and cool down of free wheeling (i.e. cycling with no resistance) to total $40 \mathrm{~min}$ of exercise. The subjects were blinded to the experiments until the conclusion of the baseline period. Subjects left the laboratory wearing an ambulatory monitor until $2300 \mathrm{hr}$ with a mean attachment time of 12:30 pm.

\section{Blood Sampling and Analysis}

Blood samples were taken in advance of the experimental sessions for the purposes of genotyping and fasting blood lipid-lipoprotein, glucose and insulin determinations. Blood samples for catecholamine determinations were obtained during the experiments as follows: at the end of the baseline period, at $30 \mathrm{~min}$ of each $40 \mathrm{~min}$ experiment, and at the conclusion of the experimental sessions while still in the laboratory but prior to attachment to the ambulatory BP monitor. Samples were drawn into anticoagulated EDTA tubes and centrifuged at $2500 \mathrm{~g}$ and $23^{\circ} \mathrm{C}$ for $6 \mathrm{~min}$. Plasma samples were transferred to storage tubes and frozen at $-80^{\circ} \mathrm{C}$ until analysis. Blood lipids-lipoproteins were determined by oxidase assays using colorimetric enzymatic methods (Cobras ${ }^{\circledR}$ Integra $^{\mathrm{TM}}$, Roche Diagnostics, Mannheim, Germany). The intra- and inter-assay coefficient of variation for the triglyceride assays were $1.6 \%$ and $1.9 \%$, respectively. Low density lipoprotein was calculated with the Friedewald equation [23]. Plasma concentrations of catecholamines were measured in a subsample of 20 men by high performance liquid chromatography (Quest Diagnostics, Wallingford, CT) with low-, normal- and high-quality control values. Epinephrine had an intra-assay coefficient of variation of $0.0 \%, 9.7 \%$ and $8.0 \%$, and an inter-assay coefficient of variation of $0.0 \%$,
$10.0 \%$ and $8.6 \%$ for the three levels of control, respectively. Norepinephrine had an intra-assay coefficient of variation of $0.0 \%, 6.1 \%$ and $4.0 \%$, and an inter-assay coefficient of variation of $0.0 \%, 8.6 \%$ and $5.8 \%$, respectively.

\section{Genotype Analysis}

DNA was isolated from anticoagulated EDTA whole blood sample and genotyped for the GNAS 393 T >C SNP (GNAS_000516.2:c.393T>C(p.Ile131Ile). Polymerase chain reaction based restriction fragment polymorphism analysis was performed using primers described by Abe et al. [7]. Amplicons were digested with FokI and fragment sizes detected by polyacrylamide gel electrophoresis. Negative and positive controls (known genotypes) and random duplicates were used as quality control. In the event of discordant results, genotyping was repeated.

\section{Statistical Analyses}

Ambulatory BP values were averaged at hourly intervals over the course of $9 \mathrm{~h}$ after the experiments since this was the timeframe when men were awake and ambulating [15]. Descriptive statistics (mean \pm SEM) were generated on all study variables for the total sample and by GNAS genotype groups. Independent t-tests determined if there were differences in subject characteristics among GNAS genotype groups and the presence or absence of a family history of hypertension. Pearson correlations examined relationships among variables that may affect the post-exercise BP response. These variables included age, body mass index, waist circumference, $\mathrm{VO}_{2}$ peak, and fasting glucose, insulin and blood lipids-lipoproteins. Chi-square was used to examine if GNAS 393 T>C was in Hardy Weinberg Equilibrium; and if there were differences among the number of men that lowered BP after exercise among GNAS genotype groups and those with and without a family history of hypertension. The GNAS 393 T>C genotype was in Hardy Weinberg Equilibrium (Table 1) $\left(\chi^{2}=0.002, p=0.958\right)$ with genotype frequencies of TT $27.1 \%(n=13)$, TC $50.0 \%(n=24)$, and CC $22.9 \%(\mathrm{n}=11)$; and allelic frequencies of $\mathrm{T}^{393} 52.8 \%$ and $\mathrm{C}^{393}$ $47.2 \%$.

Three by 3 way repeated measure ANCOVA determined if BP differed over time within and among experimental conditions (non-exercise control, LIGHT and MODERATE) and GNAS $393 \mathrm{~T}>\mathrm{C}$ genotypes with family history of hypertension as a fixed factor and high density lipoprotein as a covariate. Preliminary statistical analyses revealed that the post-exercise BP response did not differ among carriers of the GNAS $\mathrm{T}^{393}$ allele. For this reason and to provide adequate power as determined by our sample size estimates, the GNAS genotypes were combined from three to two [i.e. GNAS TT/TC $(n=37)$ and CC $(=11)]$, and three by two way repeated measures ANCOVA were performed. Significant interaction effects were found between BP and GNAS genotype. Therefore, three way repeated measures ANCOVA then determined if BP differed over time among experimental conditions (non-exercise control, LIGHT, MODERATE) within the GNAS genotype groups, and these results are displayed in Table 2. In order to determine between GNAS genotype group differences, two by two way repeated measures ANCOVA determined if BP differed over time among exercise (LIGHT or MODERATE) and non-exercise control 
Table 1. Physical Characteristics (mean \pm SEM) of the Study Sample $(n=48)$ and by GNAS 393 T $>$ C Genotype Groups

\begin{tabular}{|c|c|c|c|}
\hline Characteristics & $\begin{array}{c}\text { Total } \\
(n=48)\end{array}$ & $\begin{array}{l}\text { TT/TC } \\
(\mathbf{n}=37)\end{array}$ & $\begin{array}{c}\mathbf{C C} \\
(\mathbf{n}=11)\end{array}$ \\
\hline Age (yr) & $43.7 \pm 1.4$ & $43.8 \pm 1.5$ & $43.4 \pm 3.7$ \\
\hline Body Mass Index $\left(\mathrm{kg} / \mathrm{m}^{2}\right)$ & $29.6 \pm 0.7$ & $29.9 \pm 0.9$ & $28.7 \pm 0.8$ \\
\hline Waist Circumference $(\mathrm{cm})$ & $102.3 \pm 2.0$ & $102.6 \pm 2.4$ & $101.5 \pm 3.6$ \\
\hline Orientation Ambulatory Awake DBP (mm Hg) & $85.5 \pm 1.1$ & $85.1 \pm 1.2$ & $86.9 \pm 2.5$ \\
\hline Relative Maximum $\mathrm{VO}_{2}\left(\mathrm{ml} \cdot \mathrm{kg}^{-1} \mathrm{~min}^{-1}\right)$ & $31.1 \pm 0.9$ & $30.8 \pm 1.1$ & $32.1 \pm 1.5$ \\
\hline Total Cholesterol $\left(\mathrm{mmol} \mathrm{L}^{-1}\right)$ & $4.98 \pm 0.05$ & $4.89 \pm 0.18$ & $5.27 \pm 0.29$ \\
\hline Low Density Lipoprotein $\left(\mathrm{mmol}^{-1}\right)$ & $3.10 \pm 0.14$ & $3.02 \pm 0.16$ & $3.34 \pm 0.30$ \\
\hline Triglycerides $\left(\mathrm{mmol}^{-1} \mathrm{~L}^{-1}\right)$ & $1.61 \pm 0.14$ & $1.60 \pm 0.16$ & $1.65 \pm 0.30$ \\
\hline Epinephrine $\left(\mathrm{pmol} \mathrm{L}^{-1}\right)$ & $\begin{array}{c}310.1 \pm 12.7 \\
\quad(\mathrm{n}=20)\end{array}$ & $\begin{array}{c}342.2 \pm 11.3^{*} \\
(\mathrm{n}=16)\end{array}$ & $\begin{array}{c}279.8 \pm 22.7 \\
\quad(n=4)\end{array}$ \\
\hline Norepinephrine $\left(\mathrm{nmol} \mathrm{L}^{-1}\right)$ & $\begin{array}{c}1.04 \pm 0.12 \\
(\mathrm{n}=20)\end{array}$ & $\begin{array}{c}1.34 \pm 0.11^{*} \\
\quad(\mathrm{n}=16)\end{array}$ & $\begin{array}{c}0.74 \pm 0.22 \\
\quad(n=4)\end{array}$ \\
\hline
\end{tabular}

SBP: systolic blood pressure; DBP: diastolic blood pressure; $\mathrm{VO}_{2}$ : oxygen consumption.

$*_{\mathrm{p}}<0.05$, GNAS TT/TC $v s . \mathrm{CC}$.

Table 2. Within-Method (Exercise Intensity) Effect for the Blood Pressure Change (Mean \pm SEM) from Baseline after Exercise and Non-Exercise Control Over $9 \mathrm{hr}$ Among the Total Sample and GNAS 393 T>C Génotype Groups (95\% Confidence Interval)*

\begin{tabular}{|c|c|c|c|c|c|c|c|}
\hline & & \multicolumn{3}{|c|}{ SBP Response (mmHg) } & \multicolumn{3}{|c|}{ DBP Response (mmHg) } \\
\hline & & $\begin{array}{c}\text { Non-Exercise } \\
\text { Control }\end{array}$ & Light & Moderate & $\begin{array}{c}\text { Non-Exercise } \\
\text { Control }\end{array}$ & Light & Moderate \\
\hline \multirow{2}{*}{ Total Sample $(\mathrm{n}=48)$} & Baseline* & $125.2 \pm 1.6$ & & & $86.8 \pm 1.2$ & & \\
\hline & $\begin{array}{c}\text { Post-Pre Experiment } \\
\text { Change }\end{array}$ & $(6.7,12.4)$ & $(6.7,12.9)$ & $(2.6,9.5)$ & $(-4.5,0.0)$ & $(-3.6,0.7)$ & $(-5.1,-0.9)$ \\
\hline \multirow{3}{*}{$\mathrm{TT} / \mathrm{TC}(\mathrm{n}=37)$} & Baseline & $122.9 \pm 1.7 \dagger$ & & & $85.6 \pm 1.3 \ddagger$ & & \\
\hline & \multirow{2}{*}{$\begin{array}{c}\text { Post-Pre Experiment } \\
\text { Change }\end{array}$} & $12.4 \pm 1.2$ & $8.7 \pm 1.3^{*}$ & $6.9 \pm 1.5 \dagger$ & $-1.0 \pm 1.0$ & $-2.7 \pm 0.9$ & $-2.6 \pm 0.9$ \\
\hline & & $(9.9,14.9)$ & $(6.0,11.4)$ & $(3.4,9.9)$ & $(-3.0,1.0)$ & $(-4.6,-0.9)$ & $(-4.5,-0.8)$ \\
\hline $\mathrm{CC}(\mathrm{n}=11)$ & $\begin{array}{c}\text { Post-Pre Experiment } \\
\text { Change }\end{array}$ & $(1.6,11.7)$ & $(5.4,16.6)$ & $(-0.9,11.3)$ & $(-7.6,0.5)$ & $(-4.0,3.6)$ & $(-7.1,0.4)$ \\
\hline
\end{tabular}

* Baseline=Blood pressure average $( \pm \mathrm{SEM})$ of the pre-experiment 20 min period of seated rest; Post-Pre Experiment Change=Mean of the hourly blood pressure averages over the course of 9 hours after the experiments minus average baseline blood pressure.

$\dagger \mathrm{p}<0.05$, exercise $v s$. non-exercise control; $\neq \mathrm{p}<0.01$ GNAS TT/TC $v s$. CC.

LIGHT: $40 \% \mathrm{VO}_{2}$ peak; MODERATE: $60 \% \mathrm{VO}_{2}$ peak 
among GNAS genotype groups, and these results are displayed in Figs. (1 and 2).

In the subsample of subjects $(n=20)$ in which catecholamines were measured, repeated measures ANOVA tested if catecholamines differed over time within and among the experimental conditions and GNAS TT/TC and TT genotype groups. There were no GNAS genotype group differences in the catecholamine response so that data are presented for the entire subsample.

Sample size power calculations were conducted assuming a multivariate approach to analyzing repeated measure BP data [24]. Based upon our previous findings with the $\alpha$ adducin Gly460Trp SNP which had a minor allele frequency of
$5 \%$ [20], a series of power assessments were fit to estimated BP means and standard deviations for the experimental conditions and GNAS genotype groups. This prior research indicated a moderate effect size could be expected to detect differences in post-exercise BP among the experimental conditions and GNAS genotype groups with BP hourly change correlations of 0.50 across time. Based upon these assumptions, sample sizes of 37 men in GNAS TT/TC and 11 men in the GNAS CC genotype groups were sufficient to provide adequate power for detecting a SBP within method effect (non-exercise control, LIGHT and MODERATE) with a power of 0.827 and a SBP method by GNAS genotype interaction between GNAS genotype group effect with a power of 0.695 .
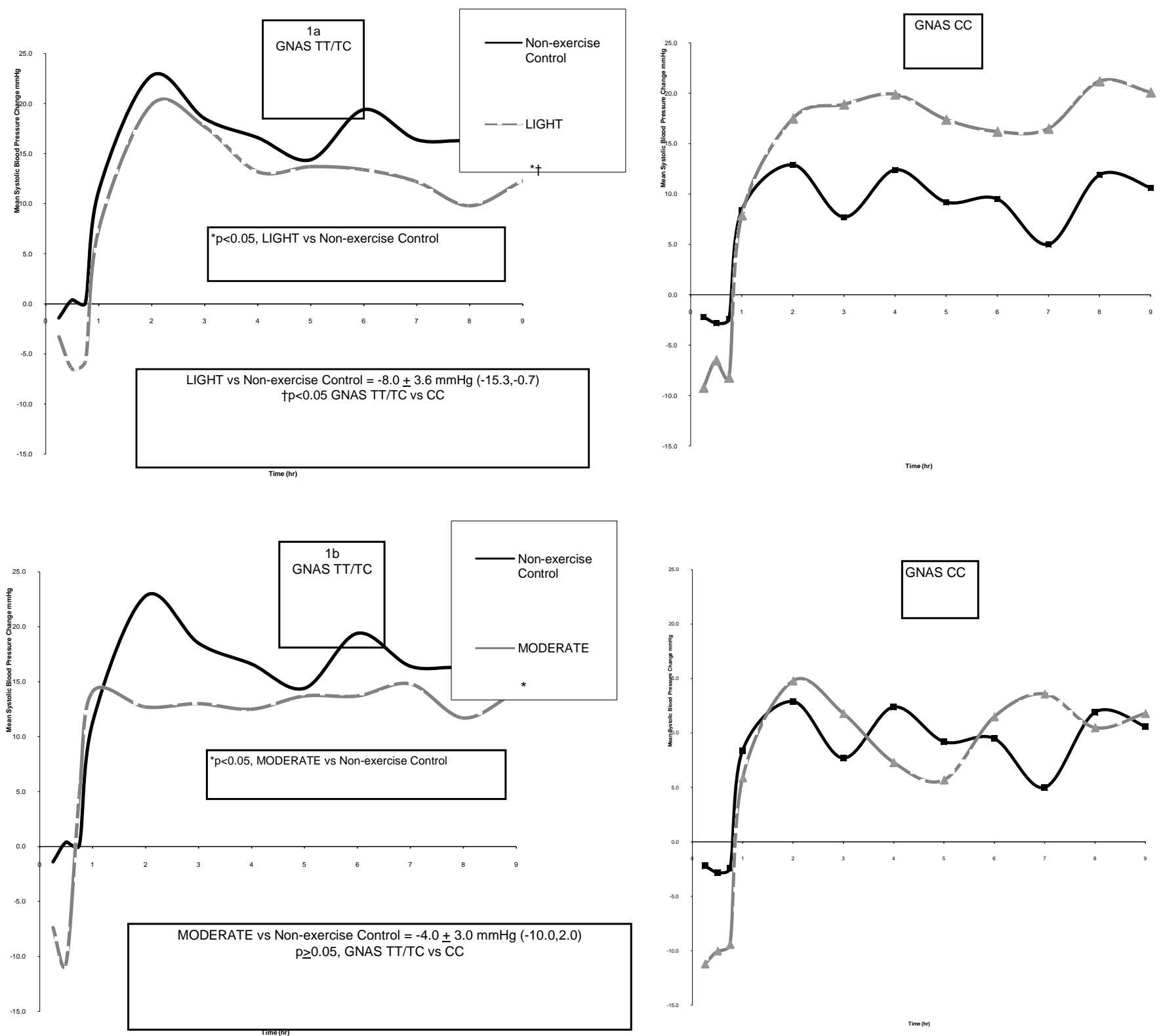

Figs. (1a and b). Mean SBP change from baseline after exercise $v$ s. non-exercise control at hourly intervals over 9 hr (1a) LIGHT and (1b) MODERATE by GNAS TT/TC $(n=37)$ and CC $(n=11)$ genotype groups. LIGHT: $40 \% \mathrm{VO}_{2}$ peak; MODERATE: $60 \% \mathrm{VO}_{2}$ peak. 
All statistical analyses were performed with Statistical Package for the Social Sciences for Windows version 14.0 with $\mathrm{p}<0.05$ established as the level of significance. Figures were drawn with Microsoft ${ }^{\circledR}$ Office 2003. BP results $($ mean \pm SEM) $(95 \%$ Confidence Interval) are initially reported for the within method effect (non-exercise control, LIGHT and MODERATE) for the initial assessment of BP change from baseline over time. Results are then presented for the main research question involving the method by genotype interaction effect of the difference in the BP change from baseline over time after exercise vs. nonexercise control between GNAS genotype groups.

\section{RESULTS}

\section{Subjects}

Subjects $(n=48)$ were overweight, Caucasian men with high normal to Stage 1 hypertension, borderline dyslipidemia [25], and below average physical fitness for men of their age [26] (Table 1). Physical characteristics were not different between GNAS genotype groups (Table 2) ( $\mathrm{p} \geq 0.05$ ), with the exception of resting catecholamines that were greater among those with the GNAS $\mathrm{T}^{393}$ allele (i.e., TT/TC) than those with the GNAS CC genotype $(\mathrm{p}<0.05)$.

\section{Total Sample BP Response}

\section{Within-Method (Exercise Intensity) Effect}

Table 2 presents the BP response from baseline after exercise compared to non-exercise control over the course of 9 h. Among the total sample, SBP increased and DBP decreased from baseline following all experimental conditions over the course of $9 \mathrm{~h}$ (Table 2) $(\mathrm{p}<0.001)$. However, SBP was increased an average of $3.5 \pm 1.5 \mathrm{mmHg}$ less from baseline after MODERATE compared to non-exercise control $(p<0.05)$ but not after LIGHT $(p \geq 0.05)$. The DBP response was not different between exercise and non-exercise control over $9 \mathrm{~h}(\mathrm{p} \geq 0.05)$.

\section{GNAS 393 T $>$ C SNP and BP Effects}

\section{Within-Method (Exercise Intensity) Effect}

Among men with the GNAS $\mathrm{T}^{393}$ allele (i.e. TT/TC), SBP increased an average of $3.7 \pm 1.6 \mathrm{mmHg}$ less from baseline after LIGHT and $5.5 \pm 1.3 \mathrm{mmHg}$ less after MODERATE compared with non-exercise control over $9 \mathrm{~h}$ (Table 2) $(\mathrm{p}<0.05)$. DBP decreased approximately $1.7 \pm 1.2 \mathrm{~mm} \mathrm{Hg}$ more from baseline after LIGHT and MODERATE compared to non-exercise control over $9 \mathrm{~h}$ (Table 2), but these differences did not achieve statistical significance $(\mathrm{p} \geq 0.05)$. Among men with the GNAS CC genotype, neither the SBP nor DBP change from baseline was different after LIGHT and MODERATE vs. non-exercise control over $9 \mathrm{~h}$ (Table 2) $(\mathrm{p} \geq 0.05)$.

\section{Interaction Method (Exercise Intensity) by Genotype Effect}

Baseline BP prior to the start of the experiments was lower among men with the GNAS $\mathrm{T}^{393}$ allele compared to men with the GNAS CC genotype $(\mathrm{p}<0.01)$ (Table 2). Figs (1 (SBP) and 2 (DBP)) display the mean change in the BP response from baseline after exercise vs. non-exercise con- trol at hourly intervals by the GNAS genotype groups. SBP increased $8.0 \pm 3.7 \mathrm{mmHg}$ less over $9 \mathrm{~h}$ after LIGHT $v s$. nonexercise control among men with the GNAS $\mathrm{T}^{393}$ allele $(-3.7 \pm 1.6 \mathrm{mmHg})$ compared to those with the GNAS CC genotype $(4.3 \pm 3.3 \mathrm{mmHg})($ Fig. 1a) $(\mathrm{p}<0.05)$ but not after MODERATE (Fig. 1b) $(\mathrm{p} \geq 0.05)$. Similarly, when carriers of the GNAS T ${ }^{393}$ allele $(-1.7 \pm 1.2 \mathrm{mmHg})$ were compared to GNAS CC homozygotes $(3.4 \pm 2.5 \mathrm{mmHg})$, DBP tended to decrease $5.1 \pm 2.8 \mathrm{mmHg}$ more over $9 \mathrm{~h}$ after LIGHT than non-exercise control (Fig. 2a) $(\mathrm{p}=0.076)$ but not after MODERATE (Fig. 2b) (p>0.05).

Among GNAS $\mathrm{T}^{393}$ allele carriers $(\mathrm{n}=37), 54.1 \%$ reported a family history of hypertension and $45.9 \%$ did not; whereas among GNAS CC homozygotes, $27.3 \%$ indicated a family history of hypertension and $72.7 \%$ did not $(\mathrm{p} \geq 0.05)$. However, $90 \%$ of the men with the GNAS $\mathrm{T}^{393}$ allele and a family history of hypertension (i.e. 18/20) had lower BP after LIGHT than non-exercise control; whereas $64 \%$ of the men with the GNAS CC genotype (i.e. 7/11) did not have lower BP after LIGHT, independent of a family history of hypertension $(\mathrm{p}<0.01)$.

\section{GNAS 393 T >C SNP and Catecholamines}

Epinephrine increased from baseline during and after exercise and non-exercise control $(p<0.001)$ (Fig. 3a). The epinephrine increase from baseline was greater during MODERATE $\left(252.8 \pm 88.4 \mathrm{pmol}^{-1}\right)$ than non-exercise control $\left(47.2 \pm 39.2 \mathrm{pmol}^{-1}\right)(\mathrm{p}<0.05)$ and LIGHT $(98.3 \pm 33.8$ $\left.\mathrm{pmol} \mathrm{L}^{-1}\right)(\mathrm{p}=0.06)$. The epinephrine response did not differ between GNAS genotype groups (GNAS TT/TC $n=16$; CC $\mathrm{n}=4)(\mathrm{p} \geq 0.05)$. Norepinephrine increased from baseline during and after exercise $(\mathrm{p}<0.001)$ but not non-exercise control $(\mathrm{p} \geq 0.05)$, with the increase during MODERATE $(3.15 \pm 0.83$ $\left.\mathrm{nmol} \mathrm{L}^{-1}\right)$ greater than non-exercise control $(0.23 \pm 0.24$ $\left.\mathrm{nmol} \mathrm{L}^{-1}\right)$ and LIGHT $\left(1.03 \pm 0.28 \mathrm{nmol}^{-1}\right)(\mathrm{p}<0.05)$ (Fig. 3b). The norepinephrine response did not differ between GNAS genotype groups (GNAS TT/TC n=16; CC n=4) $(\mathrm{p} \geq 0.05)$.

\section{DISCUSSION}

We investigated the influence of GNAS $393 \mathrm{~T}>\mathrm{C}$ on the $\mathrm{BP}$ response immediately following aerobic exercise performed at LIGHT and MODERATE among 48 Caucasian men with high normal to Stage 1 hypertension. SBP increased approximately $8 \mathrm{mmHg}$ less (Fig. 1a) $(\mathrm{p}<0.05)$ and DBP tended to decrease $5 \mathrm{mmHg}$ more (Fig. 2a) $(\mathrm{p}=0.076)$ after LIGHT vs. non-exercise control over $9 \mathrm{~h}$ among men with the GNAS $\mathrm{T}^{393}$ allele compared to GNAS CC homozygotes. Under these conditions, there were no GNAS genotype differences in the BP response after MODERATE (Figs. $\mathbf{1 b}$ and 2b) ( $\mathrm{p} \geq 0.05)$. Nearly all of the men with the GNAS $\mathrm{T}^{393}$ allele and a self-disclosed family history of hypertension had lower BP after LIGHT (i.e., 18/20) compared to nonexercise control; whereas two thirds of men with the GNAS CC genotype did not have lower BP after LIGHT (i.e. 7/11), independent of family history of hypertension $(p<0.01)$. Thus, it appears that men with the GNAS $\mathrm{T}^{393}$ allele, a family history of hypertension, and high BP appear to experience the antihypertensive effects of lower intensity, aerobic exercise more so compared to men with the GNAS CC genotype. 

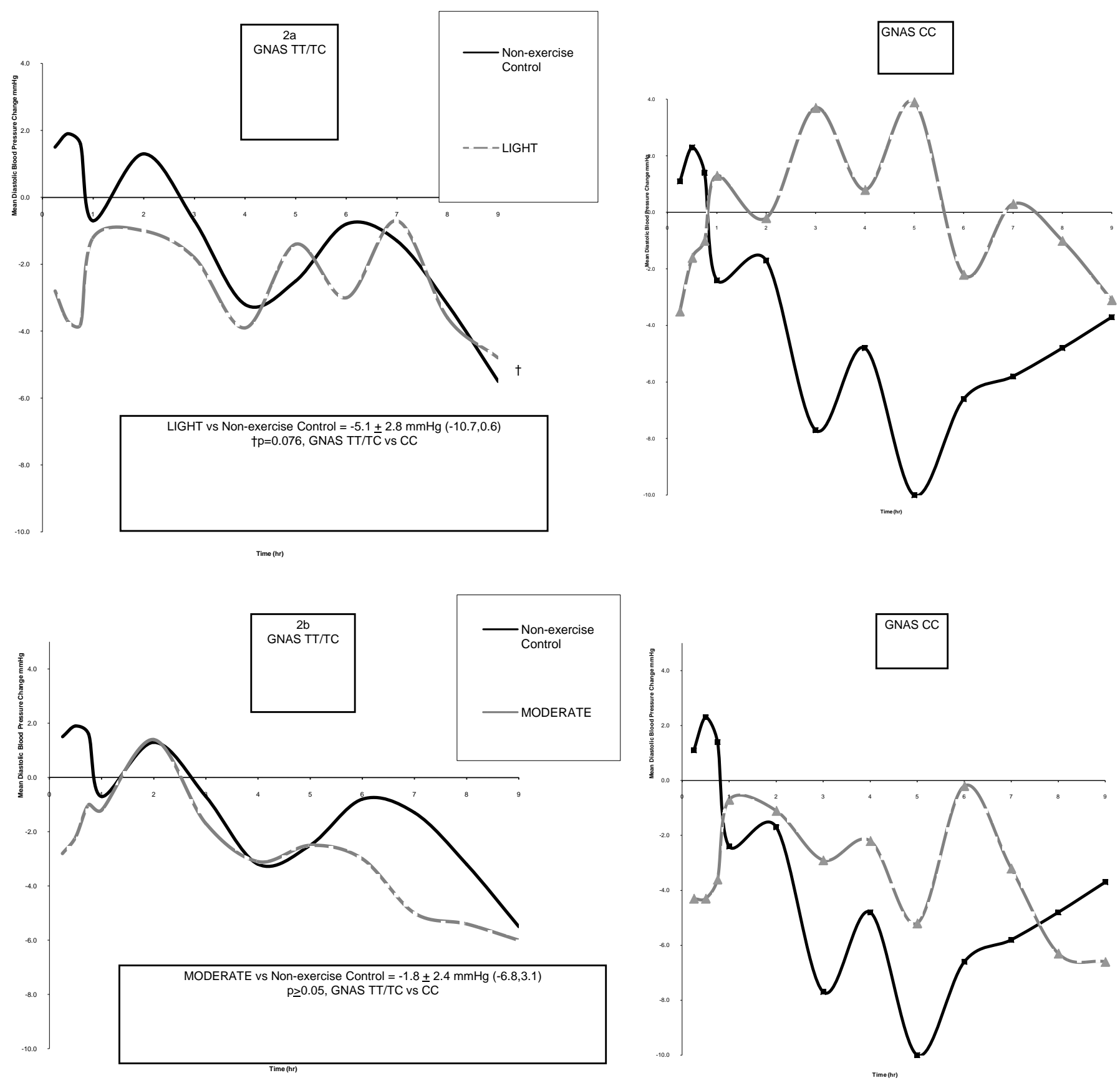

Figs. (2a and b). Mean DBP change from baseline after exercise $v s$. non-exercise control at hourly intervals over 9 hr (1a) LIGHT and (1b) MODERATE by GNAS TT/TC $(n=37)$ and CC $(n=11)$ genotype groups. LIGHT: $40 \% \mathrm{VO}_{2}$ peak; MODERATE: $60 \% \mathrm{VO}_{2}$ peak.

Our results suggest that GNAS 393 T>C SNP may be useful in differentiating between men who do and do not reduce BP after aerobic exercise. These findings are consistent with our previous reports [18-20] and support the notion that risk alleles from genetic variants in major BP regulatory systems (i.e. the renin angiotensin system and now the sympathetic nervous system) are associated with the BP lowering effects of LIGHT. The added value of a family history of hypertension combined with the GNAS $\mathrm{T}^{393}$ allele in terms of correctly classifying men who had lower BP after LIGHT than non-exercise control suggests other genetic factors that remain to be identified contribute to the antihypertensive effects of lower intensity, aerobic exercise.

GNAS $393 \mathrm{~T}>\mathrm{C}$ is a silent SNP resulting in a synonymous codon substitution that does not change the amino acid composition of the protein product. Kimchi-Safaty and colleagues [27] have recently shown that silent mutations have functional consequences due to their influence on protein folding and function that alters substrate specificity. GNAS $393 \mathrm{~T}>\mathrm{C}$ is associated with complex expression patterns that differ according to the risk status of the population and the level of sympathetic nervous system stimulation associated 

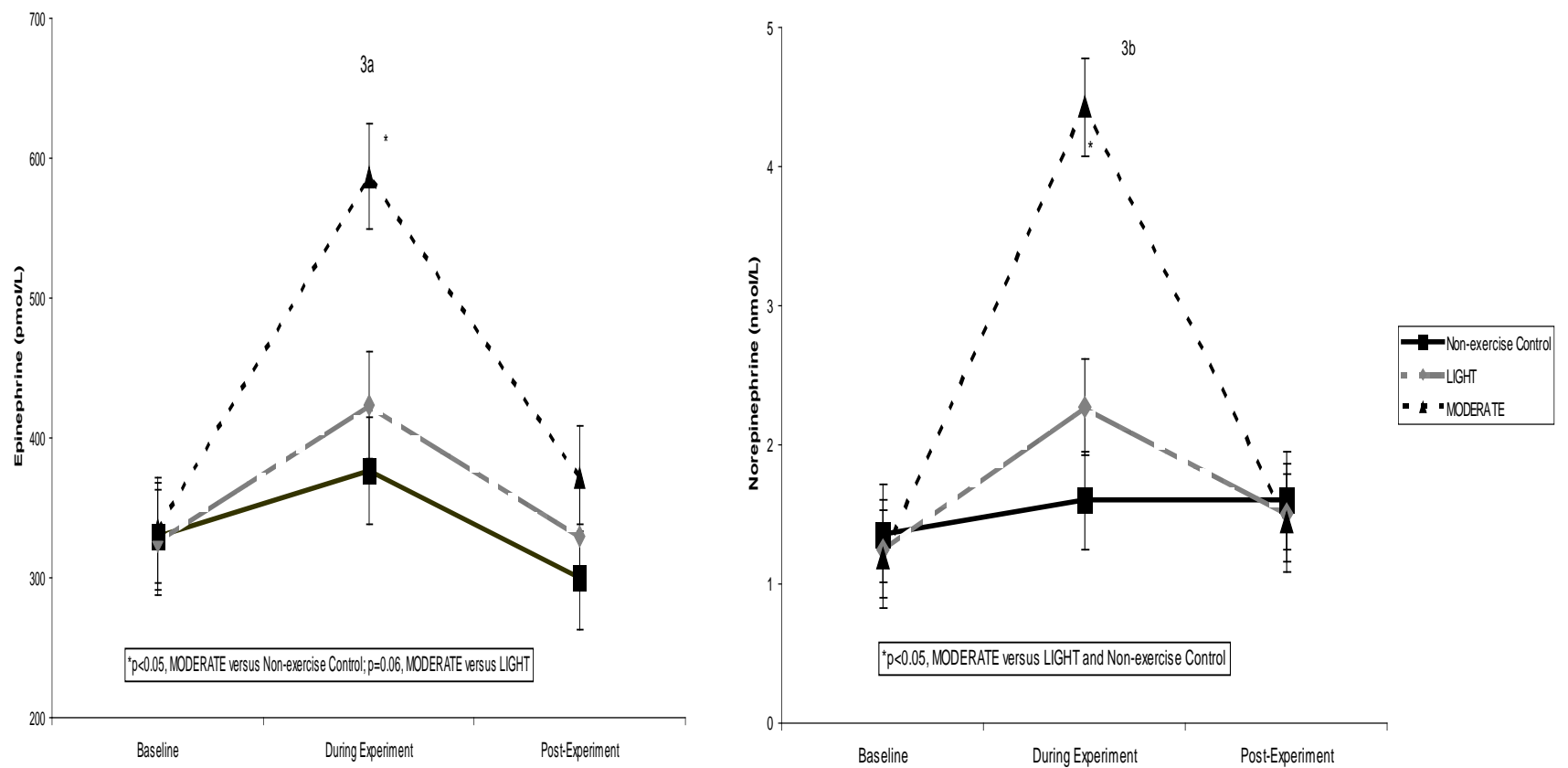

Figs. (3a and b). Epinephrine $(n=20)$ and norepinephrine $(n=19)$ response from baseline during and after exercise and non-exercise control. LIGHT: $40 \% \mathrm{VO}_{2}$ peak; MODERATE: $60 \% \mathrm{VO}_{2}$ peak.

with the environmental factor examined [5-7, 9]. Jia et al. [6] found a higher frequency of the GNAS $\mathrm{T}^{393}$ allele among Caucasian middle-aged adults with hypertension compared with those with normal BP; whereas the GNAS C ${ }^{393}$ allele tracked with higher baseline BP among the cohort with hypertension as we found in our study sample (Table 2).

GNAS $393 \mathrm{~T}>\mathrm{C}$ associations with $\mathrm{BP}$ are reported to be altered by smoking status [7], alcohol consumption [5], glucose tolerance intolerance [9], $\beta$ blockade [6] and now exercise intensity or the level of physical exertion. We found that men with the GNAS $\mathrm{T}^{393}$ allele increased BP less after LIGHT compared to non-exercise control compared to GNAS CC homozygotes; however, these genotype differences were no longer apparent at more vigorous levels of physical exertion. Sympathetic nervous system activation is directly proportional to the intensity of the exercise bout [28] as is shown in Fig. (3). The reason for the GNAS genotype BP differences we observed are not readily apparent but may be attributed to a functional impairment of $\mathrm{G}_{\mathrm{s}}$ protein $\beta$ adrenoceptor coupling among those with the GNAS $\mathrm{T}^{393}$ allele resulting in enhanced constriction of the resistance arteries at higher levels of physical exertion [5-7, 9, 10, 29].

Heightened activation of the sympathetic nervous system is implicated in the etiology of hypertension [30]; whereas decreased sensitivity to $\alpha$-adrenergic receptor stimulation, diminished norepinephrine production, and/or increased norepinephrine uptake following exercise are thought to contribute to post-exercise BP response [11]. Although resting catecholamine levels (GNAS TT/TC > CC) (Table 1) and baseline BP (GNAS TT/TC < CC) (Table 2) differed between GNAS genotype groups, there were no differences between GNAS genotype groups and the exercise induced catecholamine response. Thus, the catecholamine results did not offer any explanations for the interactions we found among GNAS genotype and the post-exercise BP response.
The strengths of our study are the stringent criteria by which the ambulatory BP phenotype was assessed and the randomized control study design. Limitations include the small sample size; however, our sample size estimates indicated adequate power to test the primary hypothesis. We purposely restricted the sample to Caucasian men because smaller population subgroups with a more homogenous genetic composition minimize genetic admixture and decrease the likelihood of finding spurious associations with the phenotype of interest [31]. GNAS $393 \mathrm{~T}>\mathrm{C}$ is located in a recombination hotspot that is in linkage disequilibrium with makers up- and down-stream. Thus, it is possible that the interactions we found between GNAS $393 \mathrm{~T}>\mathrm{C}$ and the postexercise BP response are due to other SNPs in the GNAS gene in linkage disequilibrium with GNAS $393 \mathrm{~T}>\mathrm{C}$ [4]. Overall associations among environmental factors and complex phenotypes such as the post-exercise BP response are often masked by the presence of gene-environment interactions $[5,7,19,22]$. Our findings demonstrate the importance of conducting intervention studies that examine geneenvironment interactions in order to isolate complex genotype-phenotype associations. Admittedly, they need to be validated in a larger, more ethnically diverse sample of men and women.

In summary, men with the GNAS $\mathrm{T}^{393}$ allele, a family history of hypertension, and high BP appear to experience the antihypertensive effects of lower intensity, aerobic exercise more so than do men with the GNAS CC genotype. Reasons for our findings need to be more clearly elucidated, but answers may reside in the balance achieved between vasodilator-vasoconstrictor status after stressing the genotype with 2 different levels of physical exertion. A long term goal of personalized medicine is to use genetic and clinical information to more specifically guide lifestyle interventions. Our results indicate that genetic variants in the BP regulatory pathways may eventually be useful in identifying subgroups 
of patients likely to respond to lower intensity, aerobic exercise as antihypertensive therapy.

\section{ACKNOWLEDGEMENTS}

We thank the study volunteers; agencies that enabled subject recruitment; and University of Connecticut graduate students who assisted with this study. This work was supported by an American Heart Association Grant-in-Aid $(0150507 \mathrm{~N})$.

\section{REFERENCES}

[1] Carmen G-Y, Victor S-M. Signaling mechanisms regulating lipolysis. Cell Signal 2006; 18: 401-08.

[2] Eglen RM, Bosse R, Reisine T. Emerging concepts of guanine nucleotide-binding protein coupled receptor (GPCR) function and implications for high throughout screening. Assay Drug Dev Tech 2007; 5: 425-51.

[3] Siffert WG. Protein polymorphisms in hypertension, atherosclerosis, and diabetes. Ann Rev Med 2005; 56: 17-28.

[4] Yang W, White B, Spicer EK, Weinstein BL, Hildebrandt JD. Complex haplotype structure of the human GNAS gene identifies a recombination hotspot centered on a single nucleotide polymorphism widely used in association studies. Pharmacogenetics 2004; 14: 741-47

[5] Chen Y, Nakura J, Jin JJ, et al. Association of the GNAS1 gene variant with hypertension is dependent on alcohol consumption. Hypertens Res 2003; 26: 439-44.

[6] Jia H, Hingorani AD, Sharma $P$, et al. Association of the $\mathrm{G}_{\mathrm{s}} \alpha$ gene with essential hypertension and response to $\beta$-blockade. Hypertension 1999; 34: 8-34.

[7] Abe M, Nakura J, Yamamoto M, et al. Association of the GNAS1 gene variant with hypertension depending on smoking status. Hypertension 2002; 40: 261-65.

[8] Clark CJ, Milligan G, Connell JMC. Guanine nucleotide regulatory protein alterations in the Milan hypertensive rat strain. J Hypertens 1993; 11: 1161-69.

[9] Yamamoto M, Abe M, Jin JJ, et al. Association of a GNAS1 gene variant with hypertension and diabetes mellitus. Hypertens Res 2004; 27: 919-24.

[10] Yasuda K, Matsunaga T, Moritani T, et al. T393C polymorphism of GNAS1 associated with the autonomic nervous system in young, healthy Japanese subjects. Clin Exp Pharmacol Physiol 2004; 31: 597-601.

[11] Pescatello LS, Franklin BA, Fagard R, Farquhar W, Kelly GA, Ray CA. American College of Sports Medicine position stand. Exercise and hypertension. Med Sci Sports Exerc 2004; 25: 533-53.

[12] Chobanian AV, Bakris GL, Black HR, et al. Seventh report of the Joint National Committee on prevention, detection, evaluation, and treatment of high blood pressure. JNC 7- complete version. Hypertension 2003; 42: 1206-52.

[13] Thompson PD, Crouse SF, Goodpaster B, Kelley D, Moyna N, Pescatello LS. The acute $v s$. the chronic response to exercise. Med Sci Sports Exerc 2001; 33: S438-45.

[14] Pescatello LS, Kulikowich JM. The aftereffects of dynamic exercise on ambulatory blood pressure. Med Sci Sports Exerc 2001; 33: 1855-61.
[15] Pescatello LS, Guidry MA, Blanchard BE, et al. Exercise intensity alters post-exercise hypotension. J Hypertens 2004; 22: 1881-88.

[16] Melander O. Are minor gene effects of clinical importance? J Hypertens 2007; 25: 505-07.

[17] Arnett DK, Baird AE, Barkley RA, et al. Relevance of genetics and genomics for prevention and treatment of cardiovascular disease: A scientific statement from the American Heart Association Council on Epidemiology and Prevention, the Stroke Council, and the Functional Genomics and Translational Biology Interdisciplinary Working Group. Circulation 2007; 115: 2878-01.

[18] Blanchard BE, Tsongalis GJ, Guidry MA, et al. RAAS polymorphisms alter the acute blood pressure response to aerobic exercise among men with hypertension. Eur J Appl Physiol 2006; 97: 26-33.

[19] Pescatello LS, Turner D, Rodriguez N, et al. Dietary calcium intake and renin angiotensin system polymorphisms alter the blood pressure response to aerobic exercise: a randomized control design. Nutr Metabol 2007; 4: 1

[20] Pescatello LS, Blanchard BE, Tsongalis GJ, Maresh CM, Thompson PD. Alpha adducin Gly460Trp polymorphism interacts with exercise intensity to alter the blood pressure response following endurance exercise. Clin Sci 2007; 113: 251-58.

[21] Nieminen T, Lehtimaki T, Laiho J, et al. Effects of polymorphisms in $\beta_{1}$-adrenceptor and $\alpha$-subunit of $\mathrm{G}$ protein on heart rate and blood pressure during exercise test. The Finnish Cardiovascular Study. J Appl Physiol 2006; 100: 507-11.

[22] Rankinen T, Bray MS, Hagberg JM, et al. The human gene map for performance and health-related fitness phenotypes: The 2005 update. Med Sci Sports Exerc 2006; 38: 1863-88.

[23] Freidwald WT, Levy RI, Fredickson DS. Estimation of the concentration of low density lipoproteins by a simple precipitation procedure. Clin Chem 1972; 18: 499-502.

[24] D'Amico, EJ, Neilands TB, Zambarano R. Power analysis for multivariate and repeated measures designs: A flexible approach using the SPSS MANOVA procedure. Behav Res Methods Instrum Comput 2001; 33: 479-84

[25] National Cholesterol Education Program. Third Report of the National Cholesterol Education Program (NCEP) Expert Panel on the Detection, Evaluation, and Treatment of High Blood Cholesterol in Adults (Adult Treatment Panel III). NIH Publication No. 02-5215 2002.

[26] American College of Sports Medicine. ACSM's Guidelines for Exercise Testing and Prescription. $7^{\text {th }}$ ed. In: Whaley MH, Brubaker PH, Otto RM, Eds. Baltimore, MD: Lippincott Williams \& Wilkins 2006; 79: 103-10.

[27] Kimchi-Sarfaty C, Oh JM, Kim IW, et al. A "silent" polymorphism in the MDR1 gene changes substrate specificity. Science 2007; 26: 525-28.

[28] Mazzeo RS. Catecholamine responses to acute and chronic exercise. Med Sci Sports Exerc 1991; 23: 839-45.

[29] Asano M, Masuzawa K, Matsuda T, Asano T. Reduced function of the stimulatory GTP-binding protein in beta adrenoceptoradenylate cyclase system of femoral arteries isolated from spontaneously hypertensive rats. J Pharmacol Exp Ther 1988; 246: 70918.

[30] Schlaich MP, Lambert E, Kaye DM, et al. Sympathetic augmentation in hypertension: Role of nerve firing, norepinephrine reuptake, and angiotensin neuromodulation. Hypertension 2004; 43: 169-75.

[31] Turner ST, Schwartz GL, Boerwinkle E. Personalized medicine for high blood pressure. Hypertension 2007; 50: 1-5.

(C) Pescatello et al.; Licensee Bentham Open.

This is an open access article licensed under the terms of the Creative Commons Attribution Non-Commercial License (http://creativecommons.org/licenses/by-nc/3.0/) which permits unrestricted, non-commercial use, distribution and reproduction in any medium, provided the work is properly cited. 